\begin{tabular}{c} 
journal homepage: http://ijiemjournal. uns.ac.rs/ \\
International Journal of Industrial \\
Engineering and Management \\
Volume $13 /$ No $1 /$ March $2022 / 8-17$ \\
\hline
\end{tabular}

Original research article

\title{
Providing a framework based on decision-making methods to assess safety risk in construction projects
}

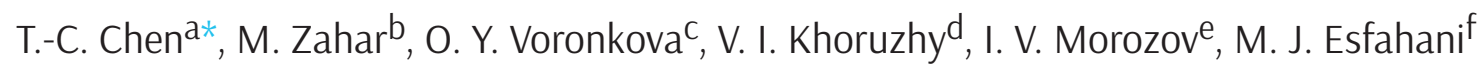 \\ ${ }^{a}$ Dhurakij Pundit University, Bangkok, Thailand; \\ b Universiti Utara Malaysia, Sintok, Malaysia; \\ ${ }^{c}$ Altai State University, Barnaul, Russia;

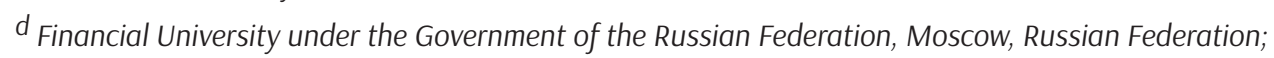 \\ e Plekhanov Russian University of Economics, Moscow, Russia;

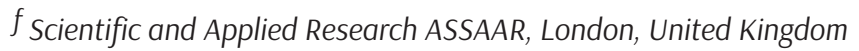

\begin{abstract}
A B STRACT
The risk management process is a systematic and logical process that should include identification, analysis, measurement, and dealing with risk-taking into account the facilities, conditions, and context of the organization. Today, work-related accidents, as one of the important factors in losing efficient manpower and Waste of capital and time, are considered a threat to the development and progress of any country. Therefore, failure to pay attention and assess the safety risk in the construction industry will cause irreparable problems and impose high costs on the project. Work-related accidents are not entirely accidental, so the most effective measures can be taken to control and reduce them while anticipating. Appropriate hi-tech in the analysis of hazards in industries is an important step in determining effective measures to reduce accidents. This study aims to use the most appropriate techniques available to identify hazards and assess the risk in order to improve safety, reduce accidents and costs and save time. In this research, to identify, evaluate and rank the safety risks of construction projects with fuzzy approach and TOPSIS method, which we have dealt with according to the importance of each risk, appropriate strategies and response programs should be applied according to them. The main finding of this research is that Excavation is the most important risky work in construction projects that needs more attention to reduce total risks.
\end{abstract}

\section{ARTICLE INFO}

Article history:

Received May 25, 2021

Revised July 21, 2021

Accepted August 5, 2021

Published online December 9, 2021

Keywords:

multi-criteria decision making;

risk assessment;

safety of construction projects;

TOPSIS method

* Corresponding author:

Tzu-Chia Chen

tzuchiachen1688@gmail.com

\section{Introduction}

Knowledge and learning are the most important resources for achieving commercial and competitive advantage in today's modern world [1]. Technological evolutions and globalization of nations are the main issues forcing organizations to estimate the risk of huge financial burdens and need planning [2], [3], [4]. Organizations that can effectively use risk man- agement of projects will become leading and successful organizations [5], [6]. In general, human beings deal with different risks throughout their lives. In other words, any action performed or any decision made can be associated with risks [7], [8]. This is mainly due to our inability to guarantee the achievement of our desired result [9], [10]. Therefore, there is also danger wherever there is a risk since these dangers threaten the favorable results [11]. Risk is variously 
defined in different areas such as safety, economy, and management, some of which include [12], [13]:

- Uncertainty about an accident

- Being in the vicinity of the danger or misfortune

- The dispersion around the mean values

- Uncertainty about damage

International organization for standardization in risk management standard defines risk as "the effect of uncertainty on organizational goals," emphasizing that risk could be positive, negative, or a deviation from the expected [14]. Moreover, the risk is often observed in the form of an event or change in the situation or indication of a result [15]. Since risk is an inevitable and manageable loss, any organization needs a specific approach to reduce the risk of the potential loss arising from a certain activity [16]. The risk management process is a logical and systematic process that should include identifying, analyzing, assessing, and dealing with risk while considering the organization's background, conditions, and facilities [14], [17]. Having a list of risks existing in a certain type of project enables project managers to review the potential risks and assess the special conditions governing the ongoing project to determine which risks can greatly endanger their projects and how to deal with them [9]. In order to succeed, organizations must use risk management principles, one of the most important dimensions of which is human resources [18], [19]. Generally, people working in a system are those who give its structure a soul. Therefore, special attention should be paid to this organizational resource in risk management [20]. Overall, any issue or organizational failure is ultimately rooted in the workforce of that organization. Lack of successful human resource management results in many threats to the organization, such as losing experts and transfer of technical knowledge [21]. This has doubled the need for risk management of human resources in the modern world. Human resource risk cannot be overlooked today due to its close relationship with value creation in companies and organizations. Research of the Institute of Human Capital reveals that risk related to human resources is the most important threat to businesses. Meanwhile, the organizational preparedness profile for business risks shows the extremely unprepared status of organizations regarding dealing with human resource-related risks. These results are congruent with the results of international studies. According to the research of the economic intelligence unit of the economist group, poor management of human resources is one of the most important threats to the long-term success of global businesses from the perspective of risk managers [21], [22].

Construction projects have always been one of the most dangerous industries in terms of the rate of damage and compensation to manpower owing to their unique nature [23]. According to statistics, occupational accidents are the third leading cause of death in the world and the second leading cause of mortality in Iran after traffic accidents. In addition, they are important health, economic and social factors in society. Notably, since occupational accidents are not completely unintentional, the most effective measures could be taken along with the prediction of these incidents in order to control and reduce them. The use of appropriate techniques in the analysis of industrial hazards is a significantly important step in determining effective measures to reduce accidents. Over the past few decades, several methods have been developed for the scientific analysis of hazards, each having different viewpoints, functions, and performances. Some of the most important causes of the development of risk analysis methods are the complexity of situations, difficulty in combining the information, and uncertainty in decisions. To date, numerous studies have been performed in industries with various methods to prioritize hazards [24], [25]. With this background in mind, safety risks were identified and assessed in construction projects in an applicable environment using fuzzy data and final ranking with the TOPSIS method.

In the rest of the paper and in section 2, the literature of the subject is reviewed. Section 3 presents the research method and its details. Section 4 presents numerical results, and Section 5 summarizes the research.

\section{Research Background}

In the field of risk management, Baghishani et al. assessed risk management in electricity distribution in North Khorasan province using a three-dimensional method. According to the results, some of the high-risk activities included eliminating blackouts from low-pressure networks, branching of subscribers and intra-city traffic, and collecting claims from subscribers [25]. Lemos et al. carried out structural risk management in Lisbon, Portugal. Risks were considered in social, legal, economic, environmental, political, and technological dimensions [25]. These 
scholars applied the HAZOP method and fuzzy logic (FL) to estimate the possibility of risk analysis failure in a refinery [8], [26]. Wang et al. used the group fuzzy decision-making approach to assess bridge risks [26]. Moreover, previous study used the FL method to model risk in construction [26]. In the field of oil industry and energy, Jafarnejad et al. identified possible risks in the excavation of oil well projects, using the fuzzy approach to assess and rank the risks [27]. Moreover, studies evaluated risk management in the area of petrochemical feed and product transportation pipelines [27]. In another study, Wang et al. studied risks in projects of energy management contract and analyzed the risks of projects, proposed the use of hierarchical and fuzzy set analysis approach to assess these risks [26]. Mojtahedi et al. applied a multi-attribute group decision-making (MAGDM) technique to determine and evaluate risks [28].

Furthermore, Yousefi et al. used a multi-objective decision-making approach to evaluate the risk of embankment dam construction projects. The results of the preceding studies prioritized domestic risks of the country in this area [27]. Loo et al. evaluated the risks of a sustainable supply chain by analyzing the conditions and reasons for failure in a fuzzy environment (case study: Saba Battery). They prioritized risks in the sustainable chains of the battery industry, considering that the possible risk factors included the possibility, severity, and ability to identify as fuzzy variables, and then prioritized them based on interdepartmental teams and by using the proposed method. To this end, fuzzy risk priority numbers were defined as fuzzy weighted geometric mean risk factors and calculated with the help of sets of alpha-cut levels and a linear programming model [27]. Zeng et al. considered fuzzy decision-making for analysis of the risk of construction projects, including human factors, location factors, materials, and equipment [29]. In the field of safety risks, Khakpour applied a fuzzy inference system to assess safety performance [29]. Furthermore, Tadic reported the danger of surfaces and objects with sharp edges and the risk of lifting and carrying loads as the first and second ranks of occupational safety hazards in the process industry using a fuzzy model [30]. Wuni et al. considered the safety risk assessment in the power distribution process using the improved ET \& BA method and its ranking with VIKOR and TOPSIS models in a fuzzy environment. According to these scholars, the two methods TOPSIS and VIKOR were able to properly rank risks and yielded relatively similar results [31]. Qazi et al. identified and prioritized risks in oil and gas projects using the fuzzy TOPSIS method. In oth- er words, they first identified the risks and then prioritized them through the fuzzy TOPSIS technique. According to their results, increased construction costs, incompatibility of the existing organizational structure with the project structure, and ultimately failure to achieve technical knowledge were three important risks that should be eliminated by oil and gas projects as soon as possible [31].

\section{Research Methodology}

In this section, the solution approach was explained in order to solve the issue of ranking safety risks of construction projects. We first determined the criteria affecting construction projects' risks, then assessed and ranked the most important safety risks in construction projects via a fuzzy approach using the TOPSIS method. In most multi-criteria decisionmaking (MCDM) techniques, decision-makers are required to determine the relative importance among the selection criteria with the weight of each of them. In case of a lack of sufficient information, the process will lead to inappropriate decisions. Meanwhile, the importance of the criteria (the weight of the criteria relative to each other) was calculated using the entropy method, which is an MCDM method for criteria weight calculation. In this method, there is a need for an option criterion matrix.

In general, entropy expresses the level of uncertainty in a continuous probability distribution. The main idea of this method is that the higher the scatter in the values of an index, the more important that index is. In the end, the final ranking is carried out by the TOPSIS method.

The Topsis technique, which is a MCDM method for prioritization based on similarity to the ideal solution, is a multi-criteria decision-making method, first introduced by Wong and Eun in 1981 [5] [32]. This technique can be used to rank and compare different options, select the best option, determine the distances between options, and group them.

One of the advantages of this method is that the criteria or indicators used for comparison can have different units of measurement and have a negative and positive nature. In other words, negative and positive indicators can be used in combination in this technique.

According to this method, the best option or solution is the closest solution to the ideal solution or option and the farthest from the non-ideal solution. The ideal solution is the solution that has the highest profit and the lowest cost, while the non-ideal solu- 
tion is the solution that has the highest cost and the lowest profit. In short, the ideal solution is obtained from the sum of the maximum values of each criterion, while the non-ideal solution is obtained from the sum of the lowest values of each criterion.

Therefore, a more appropriate approach can be taken to evaluate and rank the risks of construction projects by using Shannon's entropy model in weighing criteria relative to each other and ranking by the TOPSIS method. The research stages are presented below.

\subsection{Decision Matrix Formulation}

Solving the MADM problem is started by creating a decision matrix shown in the figure below, where $\mathrm{A}=\{$ Ai for $\mathrm{i}=1,2,3, \ldots, \mathrm{m}\}$ shows the option, $\mathrm{C}=\{\mathrm{Cj}$ for $\mathrm{j}=1,2,3, \ldots, \mathrm{n}\}$ shows the set of selection criteria, and $\mathrm{X} \mathrm{ij}$ shows the performance of the Ai option when assessed by $\mathrm{Cj}$ criteria. In this matrix, the values of quantitative criteria performance, which conventional methods can calculate, are definitive. However, the performance values of qualitative criteria are obtained based on experts' opinions and by using a Fuzzy method, as shown in Table 1 [32].

\subsection{Criteria Prioritization Value Estimation}

A triangular fuzzy number can be represented by three ordered bounds (I, M, N), where I is the lower bound, $\mathrm{M}$ is the middle bound, and $\mathrm{N}$ is the upper bound. The optimization index is a linear convex composition shown in Figure 1 [26].

In this study, fuzzy numbers were turned into definitive numbers using the widely used MinkowskiSteiner formula $\left(x=m+\frac{\beta-\alpha}{4}\right)$ as shown in Table 2 [32].

Therefore, the weight of criteria relative to each other was obtained by Shannon's entropy model following the defuzzification of the decision matrix. The stages of this method are as follows:

\subsection{Determining the Criteria's Weight}

First step: as mentioned in section 3.1, the first step includes the formation of the decision matrix (columns are criteria and rows are options).

Second step: the matrix above is normalized, and each normalized entry is called pij. In this regard, normalization includes dividing each column's entry into the total number of columns.

Table 1. Decision matrix

\begin{tabular}{|c|c|c|c|c|c|c|c|}
\hline Criterion/Option & $C_{1}$ & & $\mathrm{C}_{2}$ & $\ldots$ & & $C_{n}$ & \\
\hline$A_{1}$ & $X_{11}$ & & $X_{12}$ & $\ldots$ & & $X_{1 n}$ & \\
\hline $\mathrm{A}_{2}$ & $X_{21}$ & & $X_{22}$ & $\ldots$ & & $X_{2 n}$ & \\
\hline$\vdots$ & & $\vdots$ & & & $\vdots$ & & $\vdots$ \\
\hline$A_{m}$ & $X_{m 1}$ & & $\mathrm{X}_{\mathrm{m} 2}$ & $\ldots$ & & $X_{m n}$ & \\
\hline
\end{tabular}

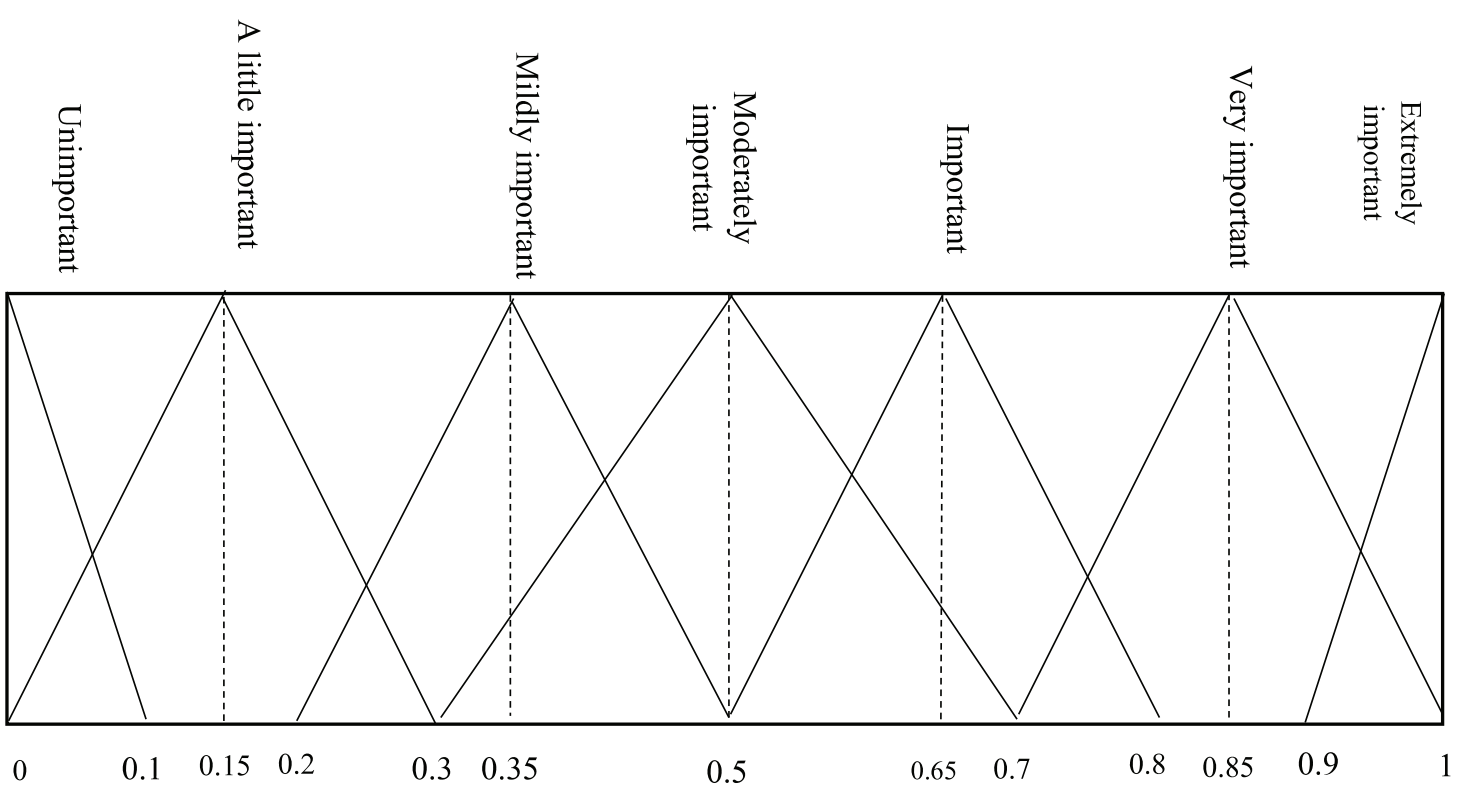

Figure 1. Membership functions for linguistic value [25,39] 
Table 2. Turning triangular fuzzy numbers into definitive numbers

\begin{tabular}{lll}
\hline Fuzzy Number & Linguistic Judgment & Definitive Fuzzy Number \\
\hline$(0 \& 0.1 \& 1)$ & Extremely important & 0.975 \\
$(0.15 \& 0.15 \& 0.85)$ & More important & 0.85 \\
$(0.15 \& 0.15 \& 0.65)$ & Important & 0.65 \\
$(0.2 \& 0.2 \& 0.5)$ & Moderately important & 0.5 \\
$(0.15 \& 0.15 \& 0.35)$ & Mildly important & 0.35 \\
$(0.15 \& 0.15 \& 0.15)$ & A little important & 0.15 \\
$(0.1 \& 0 \& 0)$ & Unimportant & 0.025 \\
\hline
\end{tabular}

Third step: each $\mathrm{E}_{\mathrm{j}}$ entropy index is calculated as shown below, and $\mathrm{k}$ is maintained in the range of zero-one as a fixed value of $\mathrm{E}_{\mathrm{j}}$.

$E_{j}=-k \sum_{i=1}^{m} P_{i j} \times \operatorname{Ln} P_{i j} \quad \mathrm{i}=1,2, \ldots, \mathrm{m}$

$\mathrm{K}$ is calculated as a fixed value, as shown below:

$k=\frac{1}{\ln (m)}$

The fourth value: in the next stage, we calculate the dj value (degree of deviation), which shows how much useful information is provided by the related index $\left(\mathrm{d}_{\mathrm{j}}\right)$ to make a decision. In this respect, the closer the measured values of the index to each other, the lower the difference between the competing options in terms of that index.

$d_{j}=1-E_{j}$

Therefore, the role of that index should be decreased in the decision-making process at the same amount.

Fifth step: afterward, we calculate the weight $\left(\mathrm{W}_{\mathrm{j}}\right)$.

$w_{j}=d_{j} / \sum d_{j}$

If the decision-maker already considers a specific weighing for the $\mathrm{j}$ index, the modified weight $\left(w_{j}^{\prime}\right)$ will be as follows:

If the

$w_{j}^{\prime}=\frac{\lambda_{i} w_{j}}{\sum_{j=1}^{n} \lambda_{i} w_{j}}$

\subsection{Final Ranking}

As mentioned, the final ranking is carried out by the TOPSIS method, which is a very robust compensatory multi-attribute decision-making technique for option prioritization through simulation of the ideal solution. This algorithm has little sensitivity to the type weighing technique, and its solutions do not change drastically. The selected option should have a minimum difference with the ideal answer and a maximum difference with the most inefficient solution in this method. TOPSIS has several advantages (compared to other prioritization techniques) such as:

- It deals with both qualitative and quantitative criteria. Its output determines the priority of options and expresses the priority in quantitative form.

- It considers the conformity and contradiction of indicators. In addition, it has a simple process and can be performed at the proper time.

- It accepts primary weight coefficients, and its results completely comply with experimental methods.

In essence, the $n * m$ matrix, which has $m$ options and $\mathrm{n}$ criteria, is assessed in the TOPSIS method. This algorithm assumes that each index or criterion in the decision-making matrix has a uniform incremental or diminishing utility. In other words, the high values obtained by the criteria in the matrix will have higher utility if they are of profit type and will have lower utility if they are of cost type. Another reason for the superiority of TOPSIS over other techniques is its ability to concomitantly use objective and subjective indicators and criteria. Nevertheless, all values attributed to the criteria should be of the quantitative 
type in order to perform mathematical calculations in the model. Therefore, qualitative values should be turned into quantitative ones.

It is recommended that the TOPSIS method is used when there is limited information and a small number of indicators. The following describes the stages of TOPSIS:

Stage 1: data matrix formation based on $n$ alternative and $\mathrm{k}$ index.

$$
A_{i j}=\left[\begin{array}{cccc}
a_{11} & a_{12} & \ldots & a_{1 n} \\
a_{21} & a_{22} & \ldots & a_{2 n} \\
\vdots & \vdots & & \vdots \\
a_{m 1} & a_{m 2} & \ldots & a_{m n}
\end{array}\right]
$$

Stage 2: data standardization and standard data formation using the equation below:

$$
\begin{aligned}
r_{i j} & =\frac{a_{i j}}{\sqrt{\sum_{k=1}^{m} a_{k j}^{2}}} \\
R_{i j} & =\left[\begin{array}{cccc}
r_{11} & r_{12} & \ldots & r_{1 n} \\
r_{21} & r_{22} & \ldots & r_{2 n} \\
\vdots & \vdots & \vdots & \vdots \\
r_{m 1} & r_{m 2} & \ldots & r_{m n}
\end{array}\right]
\end{aligned}
$$

Stage 3: determining the weight of each index $\left(\mathrm{W}_{\mathrm{i}}\right)$ : in this regard, the more significant indicators had a higher weight.

$V_{i j}=\left[\begin{array}{cccc}w_{1} r_{11} & w_{2} r_{12} & \ldots & w_{n} r_{1 n} \\ w_{1} r_{21} & w_{2} r_{22} & \ldots & w_{n} r_{2 n} \\ \vdots & \vdots & & \vdots \\ w_{1} r_{m 1} & w_{2} r_{m 2} & \ldots & w_{n} r_{m n}\end{array}\right]$

Stage 4: determining the alternative i distance from the ideal alternative (higher performance of each index), which is shown by $\left(\mathrm{A}^{*}\right)$.

$$
\begin{aligned}
& A^{*}\left\{\max _{i} v_{i j} \mid j \in \in J\right\},\left(\min _{i} v_{i j} \mid j \in J^{\prime}\right) \\
& A^{*}=\left\{v_{1}^{*}, v_{2}^{*}, \ldots, v_{n}^{*}\right\}
\end{aligned}
$$

Stage 5: determining the minimum alternative i distance (lowest performance of each index), which is shown by $\mathrm{A}^{-}$.

$$
\begin{aligned}
A^{-}\left\{\min _{i} v_{i j}\left|\max _{i} v_{i j}\right| j \in J^{\prime}\right\} \\
A^{-}=\left\{v_{1}^{-}, v_{2}^{-}, \ldots, v_{n}^{-}\right\}
\end{aligned}
$$

Stage 6: determining a distance criterion for the ideal alternative $\left({ }^{*} S_{i}\right)$ and minimum alternative $\left(S_{i}^{-}\right)$.

$S_{i}^{*}=\sqrt{\sum_{j=1}^{n}\left(v_{i j}-v_{j}^{*}\right)^{2}}$
$S_{i}^{-}=\sqrt{\sum_{j=1}^{n}\left(v_{i j}-v_{j}^{-}\right)^{2}}$

Stage 7: determining a coefficient, which is equal to the minimum alternative distance $\left(S_{i}^{-}\right)$divided by the total minimum alternative distance $\left(S_{i}^{-}\right)$and the ideal alternative distance $\left({ }^{*} S_{i}\right)$, which is shown by $C_{i}^{*}$ and is calculated using the equation below:

$C_{i}^{*}=\frac{S_{i}^{-}}{S_{i}^{-}+S_{i}^{*}}$

Stage 8: alternative ranking based on the value of $C_{i}^{*}$, which fluctuates in $1 \geq C_{i}^{*} \geq 0$. In this regard, $C_{i}^{*}=1$ shows the highest rank, whereas $C_{i}^{*}=0$ is indicative of the lowest rank.

\section{Implementation of the Proposed Method}

The decision matrix was formed, and the identified criteria were obtained through library studies and based on the opinions of experts in the field of the electric power industry and selection of construction projects contractors, as explained below.

Following the identification of risks, the possibility of occurrence of each risk and its impact on areas of $\mathrm{C}_{1}$ : time (project termination due to hazards), $\mathrm{C}_{2}$ : costs imposed by the incident, $\mathrm{C}_{3}$ : quality changes, $\mathrm{C}_{4}$ : level of human resource vulnerability, $\mathrm{C}_{5}$ : risk possibility is determined, the level of impacts on the mentioned five risk areas are prioritized, and important risks are determined. These criteria are selected through the literature [30], [33].

Moreover, In this study, the options include:

- Fire and explosion $\left(\mathrm{A}_{1}\right)$

- Working in adverse weather conditions $\left(\mathrm{A}_{2}\right)$

- Destruction $\left(\mathrm{A}_{3}\right)$

- Falling objects $\left(\mathrm{A}_{4}\right)$

- Electrocution $\left(\mathrm{A}_{5}\right)$

- Lifts and work at height $\left(\mathrm{A}_{6}\right)$

- Excavation $\left(\mathrm{A}_{7}\right)$

- Welding $\left(\mathrm{A}_{8}\right)$

- $\quad$ Scaffolding a Skeleton $\left(\mathrm{A}_{9}\right)$

In this study, A1-A9 options, which act as options in the TOPSIS method, were obtained from a survey of construction project experts. These options are 
among the most important ones that most experts have mentioned.

Decision matrix formulation: in this step, the functional values of each option are calculated based on the criteria. In this regard, the decision-maker is asked to allocate proper scores based on Figure 1, which shows the fuzzy comparisons of each criterion. Table 3 presents the decision-makers judgments.

According to Table 1, the exact values of the deci- sion matrix are shown in Table 4.

Criteria weight determination: the weight of criteria was determined in comparison to each other using the entropy model in MS Excel 2016. The results are presented in Table 5.

The final weight was obtained based on the proposed weight while considering the fuzzy form's experts' options. Table 6 shows the results obtained from Shannon's entropy model.

Table 3. Decision matrix obtained from DM judgments

\begin{tabular}{llllll}
\hline Criterion/Option & $\mathrm{C}_{1}$ & $\mathrm{C}_{2}$ & $\mathrm{C}_{3}$ & $\mathrm{C}_{4}$ & \multicolumn{1}{l}{$\mathrm{C}_{5}$} \\
\hline $\mathrm{A}_{1}$ & $(0.85 \& 0.15 \& 0.15)$ & $(0.85 \& 0.15 \& 0.15)$ & $(0.15 \& 0.15 \& 0.15)$ & $(0.65 \& 0.15 \& 0.15)$ & $(0.15 \& 0.15 \& 0.15)$ \\
$\mathrm{A}_{2}$ & $(0.85 \& 0.15$ and 0.15$)$ & $(0.5 \& 0.2 \& 0.2)$ & $(0.5 \& 0.2 \& 0.2)$ & $(0.15 \& 0.15 \& 0.15)$ & $(0.35 \& 0.15 \& 0.15)$ \\
$\mathrm{A}_{3}$ & $(0.5 \& 0.2 \& 0.2)$ & $(0.35 \& 0.15 \& 0.15)$ & $(0.65 \& 0.15 \& 0.15)$ & $(0.85 \& 0.15$ and 0.15$)$ & $(0.5 \& 0.2 \& 0.2)$ \\
$A_{4}$ & $(0.15 \& 0.15 \& 0.15)$ & $(0.15 \& 0.15 \& 0.15)$ & $(0.15 \& 0.15 \& 0.15)$ & $(0.65 \& 0.15 \& 0.15)$ & $(0.5 \& 0.2 \& 0.2)$ \\
$A_{5}$ & $(0.15 \& 0.15 \& 0.15)$ & $(0.15 \& 0.15 \& 0.15)$ & $(0.35 \& 0.15 \& 0.15)$ & $(0.85 \& 0.15$ and 0.15$)$ & $(0.35 \& 0.15 \& 0.15)$ \\
$A_{6}$ & $(0.5 \& 0.2 \& 0.2)$ & $(0.35 \& 0.15 \& 0.15)$ & $(0.5 \& 0.2 \& 0.2)$ & $(0.35 \& 0.15 \& 0.15)$ & $(0.35 \& 0.15 \& 0.15)$ \\
$A_{7}$ & $(0.65 \& 0.15 \& 0.15)$ & $(1 \& 0.1 \& 0)$ & $(0.85 \& 0.15$ and 0.15$)$ & $(0.35 \& 0.15 \& 0.15)$ & $(0.85 \& 0.15$ and 0.15$)$ \\
$A_{8}$ & $(0.65 \& 0.15 \& 0.15)$ & $(0.5 \& 0.2 \& 0.2)$ & $(0.85 \& 0.15$ and 0.15$)$ & $(0.15 \& 0.15 \& 0.15)$ & $(0.65 \& 0.15 \& 0.15)$ \\
$A_{9}$ & $(0.65 \& 0.15 \& 0.15)$ & $(0.5 \& 0.2 \& 0.2)$ & $(0.5 \& 0.2 \& 0.2)$ & $(0.85 \& 0.15$ and 0.15$)$ & $(0.65 \& 0.15 \& 0.15)$ \\
\hline
\end{tabular}

Table 4. Final matrix obtained from DM judgments

\begin{tabular}{llllll}
\hline Criterion/Option & $\mathrm{C}_{1}$ & $\mathrm{C}_{2}$ & $\mathrm{C}_{3}$ & $\mathrm{C}_{4}$ & $\mathrm{C}_{5}$ \\
\hline $\mathrm{A}_{1}$ & 0.85 & 0.85 & 0.15 & 0.65 & 0.15 \\
$\mathrm{~A}_{2}$ & 0.85 & 0.5 & 0.5 & 0.15 & 0.35 \\
$\mathrm{~A}_{3}$ & 0.5 & 0.35 & 0.65 & 0.85 & 0.5 \\
$\mathrm{~A}_{4}$ & 0.15 & 0.15 & 0.15 & 0.65 & 0.5 \\
$\mathrm{~A}_{5}$ & 0.15 & 0.15 & 0.35 & 0.85 & 0.35 \\
$\mathrm{~A}_{6}$ & 0.5 & 0.35 & 0.5 & 0.35 & 0.35 \\
$\mathrm{~A}_{7}$ & 0.65 & 0.975 & 0.85 & 0.35 & 0.85 \\
$\mathrm{~A}_{8}$ & 0.65 & 0.5 & 0.85 & 0.15 & 0.65 \\
$\mathrm{~A}_{9}$ & 0.65 & 0.5 & 0.5 & 0.85 & 0.65 \\
\hline
\end{tabular}

Table 5. Linear unscaled matrix

\begin{tabular}{llllll}
\hline Criterion/Option & $\mathrm{C}_{1}$ & $\mathrm{C}_{2}$ & $\mathrm{C}_{3}$ & $\mathrm{C}_{4}$ & $\mathrm{C}_{5}$ \\
\hline $\mathrm{A}_{1}$ & 0.1717 & 0.1717 & 0.0333 & 0.1340 & 0.0345 \\
$\mathrm{~A}_{2}$ & 0.1717 & 0.1010 & 0.1111 & 0.0309 & 0.0805 \\
$\mathrm{~A}_{3}$ & 0.1010 & 0.0707 & 0.1444 & 0.1753 & 0.1149 \\
$\mathrm{~A}_{4}$ & 0.0303 & 0.0303 & 0.0333 & 0.1340 & 0.1149 \\
$\mathrm{~A}_{5}$ & 0.0303 & 0.0303 & 0.0778 & 0.1753 & 0.0805 \\
$\mathrm{~A}_{6}$ & 0.1010 & 0.0707 & 0.111 & 0.0722 & 0.0805 \\
$\mathrm{~A}_{7}$ & 0.1313 & 0.1970 & 0.1889 & 0.0722 & 0.1954 \\
$\mathrm{~A}_{8}$ & 0.1313 & 0.1010 & 0.1889 & 0.0309 & 0.1494 \\
$\mathrm{~A}_{9}$ & 0.1313 & 0.1010 & 0.1111 & 0.1753 & 0.1494 \\
\hline
\end{tabular}


Final ranking with TOPSIS method: in the end, the final ranking was carried out using the Topsis method in Excel 2016. The results are presented in Table 7 .

As observed, risk number 7 (excavation) was ranked first in the final ranking by considering the applied criteria and the weight obtained by the criteria by entropy method, followed by options $9,3,8,1$, $5,2,4$, and 6 , respectively.

\section{Conclusion}

The nature of construction projects has created a hard and harsh image of itself due to its variables. In addition, given the simultaneous changing of the two factors of labor and work environment in such projects, it is one of the most complex and high-risk industries in the field of safety and always has a high degree of uncertainty. Therefore, failure to consider and assess safety risks in the construction industry will cause irreparable problems and impose high costs on the project.

The present study aimed to evaluate and rank construction projects' safety risks using linguistic judgments with this background in mind. To this end, a decision matrix was formed by using fuzzy sets and linguistic judgments of experts after identifying construction risks and criteria. Shannon's entropy model determined the weight of each criterion following the defuzzification of decision matrix values by the Minkowski-Steiner formula. In the end, the construction projects' safety risks were ranking applying the TOPSIS method.

In general, uncertainties in construction projects are the responsibility of the contractor and the employer (construction companies). Therefore, to manage risk in a construction project, employers are looking for ways to reduce the burden of uncertainties from the employer and transfer some of them to private builders. Using methods such as partnerships in construction, segregated contracts based on expertise, attracting private capital (such as building a house at the cost of construction on the employer's land and sharing in profits) can be a solution to reduce risk and uncertainty in construction projects imposed on the employer. .

As a discussion on the results, it can be noted that risks and uncertainties that affect contractors include design and market and depend heavily on the type of contract with the employer. Therefore, contrac-

Table 6. Normalized weight $\left(w_{j}\right)$ and final weight $\left(w_{j}^{\prime}\right)$

\begin{tabular}{llllll}
\hline $\begin{array}{l}\mathrm{m}=9 \\
\mathrm{k}=0.4551\end{array}$ & $\mathrm{C}_{1}$ & $\mathrm{C}_{2}$ & $\mathrm{C}_{3}$ & $\mathrm{C}_{4}$ & $\mathrm{C}_{5}$ \\
\hline $\mathrm{E}_{\mathrm{j}}$ & 0.4857 & 0.4337 & 0.4171 & 0.3968 & 0.4037 \\
$\mathrm{~d}_{\mathrm{j}}$ & 0.5143 & 0.5663 & 0.5829 & 0.6032 & 0.5963 \\
$\mathrm{~W}_{\mathrm{j}}$ & 0.1796 & 0.1978 & 0.2036 & 0.2107 & 0.2083 \\
$\mathrm{~W}_{\mathrm{s}} \mathrm{DM}$ & 0.5 & 0.5 & 0.5 & 0.65 & 0.65 \\
$\lambda_{\mathrm{j}} \mathrm{W}_{\mathrm{j}}$ & 0.0898 & 0.0989 & 0.1018 & 0.1370 & 0.1354 \\
$\mathrm{~W}_{\mathrm{j}}^{\prime}$ & 0.1596 & 0.1757 & 0.1809 & 0.2433 & 0.2405 \\
\hline
\end{tabular}

Table 7. Final ranking

\begin{tabular}{lll}
\hline Final Rank & Option (Risk) & TOPSIS output solution \\
\hline 1 & 7 & 0.85247 \\
2 & 9 & 0.78718 \\
3 & 3 & 0.64656 \\
4 & 8 & 0.54317 \\
5 & 1 & 0.43298 \\
6 & 5 & 0.33329 \\
7 & 2 & 0.28935 \\
8 & 4 & 0.26031 \\
9 & 6 & 0.20766 \\
\hline
\end{tabular}


tors must be careful when concluding a contract and weigh the cost according to the terms of the contract and take into account the market turmoil. A contractor's experience in this way can help him to make the right decision.

According to the present study results, excavation had the highest risk among the risk factors, followed by scaffolding a skeleton, destruction, welding, fire, explosion, electrocution, working in adverse weather conditions, falling objects, and lifts and work at height. Comparisons can be performed with this research and also other new methods like in [33], [34], which indicate the superiority of the proposed approach. The results of this study can be used by managers and those involved in this industry to take appropriate measures to reduce or eliminate the adverse effects of risks. It is suggested that in the continuation of risk management steps, after collecting and prioritizing risks, appropriate answers and solutions are identified and evaluated, and selected in the form of an appropriate model [15], [35], [36].

The main limitation of this study is the accessibility to more experts for gathering higher-quality information. Moreover, in order to develop this research, it is suggested that appropriate solutions be identified and evaluated and selected in the form of an appropriate model after risk management steps and following collecting and prioritizing risks.

\section{Funding}

This research did not receive any specific grant from funding agencies in the public, commercial, or not-for-profit sectors.

\section{References}

[1] M. Pavlović, U. Marjanović, S. Rakić, N. Tasić, and B. Lalić, "The Big Potential of Big Data in Manufacturing: Evidence from Emerging Economies," in Advances in Production Management Systems. Towards Smart and Digital Manufacturing, vol. 592, B. Lalic, V. Majstorovic, U. Marjanovic, G. von Cieminski, and D. Romero, Eds. Cham: Springer International Publishing, 2020, pp. 100107. doi: 10.1007/978-3-030-57997-5_12.

[2] A. Moshahedi and N. Mehranfar, "A Comprehensive Design for a Manufacturing System using Predictive Fuzzy Models," Journal of Research in Science Engineering and Technology, vol. 9, no. 3, pp. 1-23, 2021, doi: 10.24200/ jrset.vol9iss03pp1-23

[3] S. Rakic, I. Visnjic, P. Gaiardelli, D. Romero, and U. Marjanovic, "Transformation of Manufacturing Firms: Towards Digital Servitization," in Advances in Production Management Systems. Artificial Intelligence for Sustainable and Resilient Production Systems, vol. 631, A. Dolgui, A. Bernard, D. Lemoine, G. von Cieminski, and D. Romero,
Eds. Cham: Springer International Publishing, 2021, pp. 153-161. doi: 10.1007/978-3-030-85902-2_17.

[4] B. Lalic, U. Marjanovic, S. Rakic, M. Pavlovic, T. Todorovic, and N. Medic, "Big Data Analysis as a Digital Service: Evidence Form Manufacturing Firms," in Proceedings of 5th International Conference on the Industry 4.0 Model for Advanced Manufacturing, L. Wang, V. D. Majstorovic, D. Mourtzis, E. Carpanzano, G. Moroni, and L. M. Galantucci, Eds. Cham: Springer International Publishing, 2020, pp. 263-269. doi: 10.1007/978-3-030-46212-3 19.

[5] A. Samimi, "Risk Management in Information Technology," Prog. Chem. Biochem. Res., vol. 3, no. 2, pp. 130-134, May 2020, doi: 10.33945/SAMI/PCBR.2020.2.6.

[6] R. Rahimian, "Providing Risk Management Strategies in Procurement and Supply Processes," Adv. J. Chem. B, vol. 2, no. 4, Nov. 2020, doi: 10.22034/ajcb.2020.114274.

[7] M. Karami, A. Samimi, and M. Ja'fari, "Necessity to Study of Risk Management in Oil and Gas Industries," Progress in Chemical and Biochemical Research, vol. 3, no. 3, pp. 239-243, 2020, doi: 10.33945/SAMI/PCBR.2020.3.6

[8] N. Medic, Z. Anisic, B. Lalic, U. Marjanovic, and M. Brezocnik, "Hybrid fuzzy multi-attribute decision making model for evaluation of advanced digital technologies in manufacturing: Industry 4.0 perspective," Adv produc engineer manag, vol. 14, no. 4, pp. 483-493, Dec. 2019, doi: 10.14743/apem2019.4.343.

[9] A. Foroughi and M. J. Esfahani, "A robust AHP-DEA method for measuring the relative efficiency: An application of airport industry," MSL, pp. 93-100, Jan. 2012, doi: 10.5267/j.msl.2011.09.018.

[10] A. Foroughi and M. H. Esfahani, "An empirical study for ranking risk factors using linear assignment: A case study of road construction," MSL, vol. 2, no. 2, pp. 615-622, Apr. 2012, doi: $10.5267 /$ j.msl.2011.11.007.

[11] Q. Luo, W. Li, H. Su, and X. Chen, "Evaluating Construction Risks of Modified Shield Machine Applicable to Soft Soils Based on Fuzzy Comprehensive Evaluation Method," Mathematical Problems in Engineering, vol. 2020, pp. 1-15, Oct. 2020, doi: 10.1155/2020/8861801.

[12] F. Schutte and D. Edwards, "Business model innovation: reinventing the milkman," International journal of business and management studies, vol. 12, no. 2, pp. 1-15, 2020.

[13] D. Nel, "Allocation of risk in public private partnerships in information and communications technology," International Journal of eBusiness and eGovernment Studies, vol. 12, no. 1, pp. 17-32, Jan. 2020, doi: 10.34111/ijebeg.202012102.

[14] ISO, "The ISO 31000 standard Risk management: principles and guidelines," Geneva, 2009.

[15] S. D. Digiesi et al., "Minimizing and Balancing Ergonomic Risk of Workers of an Assembly Line by Job Rotation: a MINLP Model," Int J Ind Eng Manag, vol. 9, no. 3, pp. 129-138, Sep. 2018, doi: 10.24867/IJIEM-2018-3-129.

[16] A. Clardy, "Toward an HRD Auditing Protocol: Assessing HRD Risk Management Practices," Human Resource Development Review, vol. 3, no. 2, pp. 124-150, Jun. 2004, doi: $10.1177 / 1534484304265102$.

[17] Lisbon Accounting and Business School, Lisbon Polytechnic Institute, Lisbon, Portugal, M. G. Antunes, P. R. Mucharreira, M. R. T. Justino, and J. Texeira QuirÃ3s, "Total quality management and quality certification on services corporations," International Journal for Quality Research, vol. 14, no. 3, pp. 847-864, Aug. 2020, doi: 10.24874/IJQR14.03-13.

[18] M. Dakovic, B. Lalic, M. Delic, N. Tasic, and D. Ciric, "Systematic mitigation of model sensitivity in the initiation phase of energy projects," Adv produc engineer manag, vol. 15, no. 2, pp. 217-232, Jun. 2020, doi: 10.14743/ apem2020.2.360. 
[19] M. Kliment, P. Trebuna, M. Pekarcikova, M. Straka, J. Trojan, and R. Duda, "Production Efficiency Evaluation and Products' Quality Improvement Using Simulation,” Int. j. simul. model., vol. 19, no. 3, pp. 470-481, Sep. 2020, doi: 10.2507/IJSIMM19-3-528.

[20] S. Rakic, M. Pavlovic, and U. Marjanovic, "A Precondition of Sustainability: Industry 4.0 Readiness,” Sustainability, vol. 13, no. 12, p. 6641, Jun. 2021, doi: 10.3390/su13126641.

[21] M. Meyer, G. Roodt, and M. Robbins, "Human resources risk management: Governing people risks for improved performance," SA j. hum. resour. manag., vol. 9, no. 1, pp. 1-12, 2011, doi: 10.4102/sajhrm.v9i1.366.

[22] N. Zivlak, S. Rakic, U. Marjanovic, D. Ciric, and B. Bogojevic, "The Role of Digital Servitization in Transition Economy: An SNA Approach," Tehnicki vjesnik Technical Gazette, vol. 28, no. 6, pp. 1912-1919, 2021, doi: 10.17559/TV-20210325083229.

[23] M. A. McDonald, H. J. Lipscomb, J. Bondy, and J. Glazner, “'Safety is everyone's job:' The key to safety on a large university construction site," Journal of Safety Research, vol. 40, no. 1, pp. 53-61, Jan. 2009, doi: 10.1016/j. jsr.2008.12.005.

[24] O. Tsimer, V. Repeta, Ukrainian Academy of Printing, Faculty of Publishing, Printing and Information Technologies, Lviv, Ukraine, I. Myklushka, and Ukrainian Academy of Printing, Faculty of Publishing, Printing and Information Technologies, Lviv, Ukraine, "Analysis of quality factors for digitization process of old books," J. Graph. Eng. Des., vol. 11, no. 2, pp. 5-9, Dec. 2020, doi: 10.24867/JGED-2020-2-005.

[25] T. de Lemos, D. Eaton, M. Betts, and L. T. de Almeida, "Risk management in the Lusoponte concession-a case study of the two bridges in Lisbon, Portugal," International Journal of Project Management, vol. 22, no. 1, pp. 63-73, Jan. 2004, doi: 10.1016/S0263-7863(03)00013-9.

[26] Y.-M. Wang and T. M. S. Elhag, "A fuzzy group decision making approach for bridge risk assessment," Computers \& Industrial Engineering, vol. 53, no. 1, pp. 137-148, Aug. 2007, doi: 10.1016/j.cie.2007.04.009.

[27] Jafarnezhad Ahmad and Yousefi Zenouz R., "A Fuzzy Model of Ranking Risks at Petropars Company's Excavation of Oil Well Projects," Journal of Industrial Management, vol. 1, no. 1, pp. 21-38.

[28] S. M. H. Mojtahedi, S. M. Mousavi, and A. Makui, "Project risk identification and assessment simultaneously using multi-attribute group decision making technique," Safety Science, vol. 48, no. 4, pp. 499-507, Apr. 2010, doi: 10.1016/j.ssci.2009.12.016.

[29] J. Zeng, M. An, and N. J. Smith, "Application of a fuzzy based decision making methodology to construction project risk assessment," International Journal of Project Management, vol. 25, no. 6, pp. 589-600, Aug. 2007, doi: 10.1016/j.jpproman.2007.02.006.

[30] D. Tadic, M. Djapan, M. Misita, M. Stefanovic, and D. D. Milanovic, "A Fuzzy Model for Assessing Risk of Occupational Safety in the Processing Industry," International Journal of Occupational Safety and Ergonomics, vol. 18, no. 2, pp. 115-126, Jan. 2012, doi: 10.1080/10803548.2012.11076922.

[31] I. Y. Wuni, G. Q. Shen, and B.-G. Hwang, "Risks of modular integrated construction: A review and future research directions," Front. Eng. Manag., vol. 7, no. 1, pp. 63-80, Mar. 2020, doi: 10.1007/s42524-019-0059-7.

[32] A. Qazi, A. Shamayleh, S. El-Sayegh, and S. Formaneck, "Prioritizing risks in sustainable construction projects using a risk matrix-based Monte Carlo Simulation approach," Sustainable Cities and Society, vol. 65, p. 102576, Feb. 2021, doi: $10.1016 /$ j.scs.2020.102576.
[33] M. Weber and C. G. Chatzopoulos, "Digital customer experience: the risk of ignoring the non-digital experience," Int J Ind Eng Manag, vol. 10, no. 3, pp. 201-210, Sep. 2019, doi: 10.24867/IJIEM-2019-3-240.

[34] A. Carvalho Alves et al., "A symbiotic relationship between Lean Production and Ergonomics: insights from Industrial Engineering final year projects," Int J Ind Eng Manag, vol. 10, no. 4, pp. 243-256, Dec. 2019, doi: 10.24867/ IJIEM-2019-4-244.

[35] A. Gialos and V. Zeimpekis, "Testing vision picking technology in warehouse operations: Evidence from laboratory experiments," Int J Ind Eng Manag, vol. 11, no. 1, pp. 19-30, 2020, doi: 10.24867/IJIEM-2020-1-24.

[36] L. Hudáková Stašová, "Evaluating the Use of the Activity Based Costing Method in the Construction Industry in the V4 Countries," Int J Ind Eng Manag, vol. 10, no. 4, pp. 257-268, 2019, doi: 10.24867/IJIEM-2019-4-245. 